\title{
Dreams and Realities for South Africa: Use of Official Languages Act, 2012
}

\author{
Aaron Mnguni \\ Correspondence: Aaron Mnguni, Communications Department, Faculty of Humanities, Central University of \\ Technology, FS, Mothusi Road 2, Welkom, South Africa.
}

Received: November 4, 2020

Accepted: November 26, 2020

Online Published: December 13, 2020

doi:10.11114/smc.v9i1.5104

URL: https://doi.org/10.11114/smc.v9i1.5104

\begin{abstract}
Language policies are the cornerstone that establish and maintain communication amongst people. Proper communication, particularly amongst speakers of many languages in a country such as South Africa hinges heavily on perceptions regarding the status of the languages used in that specific country. According to the Republic of South African Constitution (Act 108 of 1996), South Africa has eleven official languages. Nine of these official languages (the indigenous African languages), are regarded as historically disadvantaged, while the remaining two, viz. English and Afrikaans enjoyed official recognition under the then 'apartheid' era that lasted until 1994. The previously disadvantaged African languages still lag in terms of development, when compared to English and to a lesser extent, Afrikaans. To address this challenge and reverse the status quo, several measures have been undertaken by government, including the passing of an Act called, Use of Official Languages Act, 2012. This Act aims at managing the use of the official languages optimally, with special emphasis on the previously marginalised languages. South Africa is known for developing good language policies but often criticised for producing such good policies for one good purpose only - to display them in office shelves. Following this state of affairs, this article therefore examines the implementation challenges regarding this Act and suggest what could be done to successfully implement it in South Africa. Second, the article also seeks to alleviate the perceived apathy in implementing language policies, particularly in South Africa, and with implications for Africa as a whole.
\end{abstract}

Keywords: African languages, development, policy, implementation, South Africa

\section{Introduction}

During the early part of 2019, Dr Sally Maepa, who is Project Manager at Pan South African Language Board (PanSALB), lamented at the failure of many governmental institutions to comply with the Act, Use of official Languages Act, 2012, as prescribed by the South African government

(https://www.youtube.com/watch?v=W6aSKfMqpSM). Following the public hearing in 2017, it became obvious that little is being done to comply and implement this Act. Since 1994, much has been said and written about the role of the Republic of South African government regarding language development. Most debates have been about the lack of decisiveness and leadership in effectively ushering a new, profound and meaningful change in the language scene often dominated by the use of adventitious languages in South Africa.

The Constitution of the Republic of South Africa, 1996 (Act 108 of 1996) pronounces 11 official languages, viz. Sepedi (N. Sotho), Sesotho, Setswana, Siswati, Tshivenda, Xitsonga, Afrikaans, English, isiNdebele, isiXhosa and isiZulu. The Department of Arts, Culture, Science and Technology under the then Minister Dr Ben Ngubane, launched the Language Policy Framework on 18 and 19 March 2003. Although the Policy Framework was an ambitious plan to address the linguistic challenges in South Africa, it was unfortunately not well-received, particularly amongst Sotho and Nguni language speakers whose languages had to be used interchangeably in government services. In a clear departure from the 2003 Policy Framework and contrary to expectations, the Department of Arts and Culture passed a piece of legislation named, Use of Official Languages Act, 2012 (Act No. 12 of 2012).

In their daring work, Kaschula and Docrat (2015) argue that South Africa is like a "policy superhighway," implying that many policies are created meticulously and without end, but sadly found wanting in the actual policing of those policies. Webb (n.d. 1) argues that even though South Africa has significant language policy development which is founded on the statutory commitment to the promotion of African languages, African languages are still worse off than they were 
before 1994. While appreciating these criticisms, however, it should always be borne in mind that language development is quite a complex exercise and often multi-faceted and requires ever-vigilant practitioners to maintain a balanced stance that ensures peaceful coexistence amongst all members of the community.

Romaine (1994: 1) cites Chomsky as saying that questions of language are basically questions of power. Thus, this Act, Use of Official Languages Act, 2012 (Act No. 12 of 2012) is seen as a milestone in the history of the Republic of South African legislation. Even though there is development in this particular area which glorifies South Africa as a paragon of democracy in Africa, yet the words of wisdom expressed by Schmied (1991: 165) when he lamented that English, surprisingly is still largely perceived by the Third World as possessing certain qualities that other languages such as African languages do not have. It could be argued without any contradiction that in South Africa in particular, having good legislation does not necessarily translate into good service delivery.

The Pan South African Language Board Act (PanSALB) (Act No. 59 of 1995), a piece of good legislation could serve as an example here, and following the views of the then Deputy Chairperson Dr Neville Alexander (who later resigned as a result), the Board's activities were frustrated by lack of financial muscles as well as by political interference (Ngcobo, 2007:13). Also, on 13 January 2016, then Minister of Arts and Culture Nathi Mthethwa, dissolved PanSALB for poor performance and lack of leadership. Given this reality, this article therefore attempts to examine why well-meaning policies in language such as the Use of Official Languages Act, 2012, do not generally yield some of the intended positive outcomes in South Africa. This study therefore attempts to contribute to the language policy implementation literature in the Republic of South Africa, which could have lessons also for the wider African readership, where English or another foreign language such as Portuguese or French may still be regarded as 'divinely' anointed with special innate powers.

Several studies have been conducted in South Africa by internationally acclaimed scholars such as Webb and many others, all pointing to a possible challenge in the language policy development process. Most studies done, however, are based on pure general policy challenges. On the contrary, this paper pursues a systematic evaluation process, which demands that actual living condition of the people need to be transformed when a policy is implemented. Grin (2003) amongst several other related scholars, presents arguments in the process of solving this challenge of the language policy implementation, rather than using a general policy approach which may be found wanting and costly in the linguistic environment because of its many complexities.

\subsection{Problem Statement}

Wright (2002) argues that people charged with the task of implementing South Africa's language policy have probably realised that notional acceptance of the value of multingualism is not a guarantee that implementation will be a natural development. Consequently, even though South Africa has created some language policies that are recognised world-wide as progressive, for example, the Constitution (Act 108 of 1996), and yet there is little progress and complete transformation achieved, in the implementation of these policies. Regarding languages, this challenge affects mostly the speakers of the historically marginalised indigenous African languages such as isiZulu, Xitsonga, Tshivenda, isiNdebele, Siswati, isiXhosa, Sepedi (N. Sotho), and Setswana. Although the indigenous African languages are also official languages, their status appears nominal. This affects about 74,9\% of citizens in the Republic of South Africa as shown by the Census of the Republic of South Africa of 2011.

Furthermore, Wright (2002) argues that language practice or implementation of a society is bound to transform in response to deeply rooted social and linguistic forces that are only amenable to policy interventions. Looking at this pronouncement by Wright, arguments such as official languages or at best some official languages are not given adequate human and financial resources, for example, emanating from the policy development process. This challenge also results in some citizens questioning if the pre-1994 language era dominated by the official languages of English and Afrikaans was not better catered for by the then 'apartheid' government, compared to the present language situation? (Maphalala, 2000).

Failure to implement the Use of Official languages Act, 2012, creates many challenges for the Republic of South Africa. Biznews (https://www.biznews.com/premium/2018/06/28/english-language-business), argues that according to Statistics South Africa, only 8.4\% of the South African households speak English. In actual figures, this translates to 4.7 million out of a total population of 56 million people. The use of English willy-nilly has thus serious implications in communication, both at the formal as well as informal contexts. This for example, affects production at work as employee fail to completely understand the business direction, communication amongst employers and with the employee may be weak, and so forth. This could lead to unnecessary confrontations in the workspace. Thus, South Africa cannot meaningfully change the status quo emanating from the apartheid era that existed before 1994. 


\subsection{The Research Paradigm}

The research paradigm followed in this study is Afrocentric-indigenous. This approach is focused largely on social transformation through fairness and social justice, particular to the previously marginalised African languages. The issue of the use of the African languages is aimed at ensuring that declaring the African languages as official languages is not just a nominal exercise, and also that the African languages are fairly recognised as fundamental in building and strengthening democracy, as opposed to what the old dispensation did by branding them negatively as a source of social disunity. This paradigm highlights the societal power structures emanating from language use, and then allows participation and empowerment of the ordinary members of the public. It is through the participation of the public through using their languages that equality and redress in the community that was beset by elements of institutionalised injustices and oppression could be aptly understood. It is for this reason that this paradigm is appropriate in developing countries, like South Africa.

\section{Literature Review}

Alexander (2004:122) remarks that the introduction of exemplary language policies in South Africa does not look like it would bridge the gap between policy documents and real-life practice. He is of the view that politicians are not likely to make any dramatic change to this, and as a result, South Africa will go the way of the rest of Africa, with a few exceptions, where French, Portuguese and English have continued to be dominant languages after the respective countries attained their freedom. During struggles for liberation, there is usually prospect that something positive will happen with regards to promoting the African languages, but as soon as the independence is won, the former colonial power's languages run the show.

In the abstract of his paper, Hill (2010:41) argues that the constitutional commitment in South Africa has not succeeded to create a concrete legislative and administrative agenda, thus creating what he calls a 'policy gap'. This 'policy gap' has been attributed by some language policy critiques, to policy implementation. While Hill does not seem to concur fully with the policy critiques, nevertheless it is acknowledged that there are scholars who concluded that there are some challenges with regards to language policy implementation in South Africa.

Webb (n.d.:1) supports other scholars who argue that language management (policy development and implementation) in Africa have largely failed to be effective, despite being built on good statutory foundation. He further argues that in South Africa, for example, there are good policies which have little resemblance with the actual practice. The consequences of ineffective language policies result in untold sufferings for the majority of citizens such as unequal social opportunities, unequal economic and educational development, and so forth. Webb (n.d.:5) identifies five reasons for the multilingual language policy failure in South Africa, viz. political, economic, sociolinguistics, theoretical and cultural.

\subsection{Political}

Political regimes tend to influence the language regimes. The South African government is seen as wanting to have a language of power, which in this case is English. As a matter of fact, some politicians do not seem to fully support multilingualism and merely offer lip-service, while at heart they are bent on glorifying the English language.

\subsection{Economic}

The belief here is that one language will allow the economy to develop much better than using several languages. Again, the issue of competing globally in the economic sphere necessitates the use of one language, viz. English.

\subsection{Sociolinguistics}

In terms of this aspect, African languages are perceived as not ready to take a meaningful role in high-function formal contexts. Also, concepts such as mother-tongue and so forth are associated with the previous Apartheid dispensation in South Africa, and thus consequently discourage multilingualism. As a result of the past, most people prefer English as opposed to Afrikaans, and the African languages are not even brought to the equation.

\subsection{Theoretical}

The multilingualism policy is not argued adequately on the theoretical grounds. This aspect leads to confusion on the implementation of the language policy, and thus pushes the scale in favour of just ignoring the language policy.

\subsection{Cultural}

The cultural character of the majority of South Africans may contribute towards non implementation of the policy, for example, where people are opposed to the policy because it fundamentally changes the status quo, and in the process limits their benefits or perceived benefits.

De Kadt (2005:1) is of the view that the use of the African ethnic identities by the Apartheid government in the 
Republic of South Africa to further entrench segregation and discrimination delegitimised the use of these identities as a political tool after the demise of the Apartheid dispensation in 2004. According De Kadt, while this stance by the then government reaped fruits such as political stability as well as aided in avoiding inter-ethnic tension in the post-Apartheid South Africa, this has, however, seriously dented the political value in developing any indigenous African language. The fact that most politicians in South Africa address the general public using English rather than the indigenous African languages, even though most of the South African citizens speak African languages, clearly amplifies this assertion. The crucial question is, if the political leaders who are supposed to lead by example, do not seem too much concerned with the use of the African languages when addressing the nation and communicating among themselves, how much damage is done in the minds of the young and adult speakers of these languages? This certainly contributes towards the challenge where the status of the African languages is just nominal.

Ngcobo (2007:2) sees language planning in South Africa as amongst the best in the world. He, however, laments that such policies are bedevilled by language policy implementation. He goes on to argue that the challenge in the implementation lies in the fact that the South African language policy development initiatives are status-driven with underrated corpus development. By this he implies that if citizens supremely consider the status given by legislators over and above the role of language professionals in modernising the language, language policy implementation will seriously suffer. In short Ngcobo (2007:17) says that even though the status of the language policy in South Africa could be regarded as successful, questions about the implementation will overshadow any pat on the country's shoulders regarding such achievement. He finally suggests developing of learning material, encouraging people to use African languages in all domains as well as making use of technology as strategies to implement language policy.

While Ngcobo's views (2007) hit the nail on the head as shown in the preceding paragraph, Grin (2003: 43) further elaborates on the conditions necessary for policy successes, viz. capacity, opportunity and desire.

\section{- capacity}

African languages speakers need to be capacitated by government. This means that they should be able to use the African languages when communicating amongst themselves as well as with government officials and find it easy to say anything they want in these languages, with ease. It should not only be possible but be encouraged for a new graduate in chemistry for example, to ask to be interviewed in their preferred language of communication in terms of the Constitution of the Republic of South Africa (Act 108 of 1996). This cannot work well unless there is a strong working relationship between the government arms such as National Language Unit, National Language Service, Pan South African Language Board, and others.

\section{- opportunity}

The speakers of the African languages need opportunities to use their languages. To know a language without using it in official and important functions, relegate that language to a lower status. Use Official Languages Act, 2012 allows speakers of the African languages an opportunity to interact with government, which is something that has been ignored in the past. In other words, this is an opportunity that will allow the African languages to be relevant in the market.

\section{- desire}

The third aspect looks at the willingness of the speakers of the African languages to use their languages. The government can push up to a certain limit, but the speakers themselves need to feel proud about their languages and use them as they currently do with languages such as English. Using African languages does not mean that other languages such as English or Afrikaans should be thrown away, but African languages could be used alongside these languages. In short, government needs to encourage other structures such as political parties, community organisations such as churches, associations of authors, and so forth, to work jointly with government in building a new interest in the African languages and by doing this, create a desire to use these languages.

Perhaps the words of De Kadt (2005:4) that "implementation of the policy that does exist simply does not appear to be taking place," is an important statement that sums up the South African situation in as far as language policy implementation is concerned. Brock-Utne and Holmarsdottir (2004:81) further strengthen this argument when they say that in "South Africa the policy (language policy in education) is clearer, but the implementation of the policy leaves much to be desired." This is putting the challenge squarely on implementation, which seems to be the weakest link in the whole policy development process in South Africa.

\section{Use of the Official Languages Act, 2012}

According to Jacobs, Power and Calland (2001: 29), "throughout the apartheid era, South Africa's increasingly paranoid white minority government suppressed access to information - on social, economic and security matters - in an effort to 
stifle opposition to its policies of racial supremacy." Amongst other ways of stifling opposition to debates, was the use of foreign languages that many of the citizens in the country could not effectively use. It is no wonder then that the African languages and their speakers were often viewed with some suspicion. Jacobs, Power and Calland (2001: 30) further cite Ojo, Nigerian Executive Director of Media Rights Agenda, as saying, "many governments appear to think they can only govern effectively if they operate in total secrecy and their citizens do not know what they are doing, supposedly on behalf of the larger population." It could not therefore be business as usual for the new political dispensation in South Africa, if languages spoken by the majority of citizen remain marginalised.

To address the challenge regarding the official languages and African languages particularly, Use of the Official Languages Act, was enacted in October 2012. This Act was passed after a period of about nine years' silence since 2003 when the National Policy Framework was launched. To rub salt on the wound, it took the effort of an individual in 2009, to force the 'seemingly reluctant' government to come to the party in terms of starting the process that ultimately resulted in the passing of this Act. The government went all out to legitimise the policy process although structures such as the South African Translators' Institute (SATI) were not really excited about the way in which government set out to comply with the court ruling, and also especially that the Bill and subsequently the Act differed significantly from the 2003 Policy Framework which required then that government use at least six official languages viz. English, Afrikaans, Xitsonga, Tshivenda, one from the Nguni group and one from the Sotho group interchangeably, in some of the public translations.

A brief outline of the Act is discussed below:

According to Section 2, the objects of the Act (Use of the Official Languages Act, 2012) are as follows:

3.1. regulate and monitor the use of official languages for government purposes by national government

3.2. promote parity of esteem and equitable treatment of official languages of the Republic

3.3. facilitate equitable access to services and information of national government

3.4. promote good language management by national government for efficient public service administration and to meet the needs of the public.

The objects of this Act are important, especially in the South African context. It must be noted that all the four objects mentioned in the Act have got little to do with the action of the public. It is the government that is the main actor. According to Grin (2003:24), there are basically three reasons why a state will intervene in the issues of a language, viz. moral, welfare and a bridge between moral and welfare considerations. Moral considerations have to do with Constitutional rights of the citizens and complying with these; welfare considerations look at the total welfare to the society if language matters are addressed - in other words, to address these challenges is tantamount to using resources appropriately. Finally, the last aspect by Grin (2003:24) jointly look at the two considerations. An important argument in this paragraph is that government's intervention removes the responsibility from the public who should ultimately benefit from this exercise. The public end up as observers, relying on government to see to it that the mission of the Act is accomplished. When government is not doing as per intention, an empty space is created in terms of who should put their feet down immediately and call upon government to account.

The Act (Use of Official Languages Act, 2012) further requires the development and adoption of a language policy by agencies such as national department, national public entity and national enterprise (Section 4 of the Act). Section 4 (3) urges these agencies (where this policy will be applied) to take practical and positive measures with regards to uplifting and advancing the status and the use of historically marginalised indigenous languages. Regarding the historically marginalised indigenous languages, perhaps, government has created an 'escape clause' for itself in this aspect. Ngcobo (2007:13) supports Webb that 'escape clauses' such as not giving clear definition on crucial language issues, tend to undermine language stipulations. For example, what would put pressure on language units to recognise one of the youngest official languages such as isiNdebele, whose speakers continue to feel threatened as a result of the past political dispensation? Most language units would be tempted to go for bigger and better-known indigenous languages such as isiZulu, isiXhosa, Sesotho, and so forth, at the expense of the other official languages and in the process, and by doing this, easily comply with the stipulations of this Act. And this, unfortunately, would be contrary to the spirit of the Act.

Section 5 of this Act (Use of Official Languages Act, 2012), requires the Minister to establish a National Language Unit in the Department. The Unit will be responsible for a range of language activities such as regulating the use of the official languages, promotion of parity, management, co-ordination function as well as other related functions that will be deemed necessary by the Minister. The actual function of monitoring the use of official languages and compliance with the language policy lies with the language unit. Challenges regarding language structures have been well documented in South Africa. Some examples in this, could be financial constraints, lack of adequate human resources, alleged corruption, and so forth, which continue to bedevil language structures such as PanSALB, which the envisaged language units are not in any way inoculated from such. 


\section{Discussion}

South Africa is currently engaged with the process of decolonisation while at the same time building a nation on new ethos. The nation building process raises the importance of the African language, and consequently the culture. However, this important process of transformation can never safely and lackadaisically be left in the midwifery of a foreign language tool. One needs a local language or languages, in the case of South Africa, the identified official languages as a medium of ushering this process of decolonisation and nation building. African languages can never thrive and compete successfully against the colonial languages without initiative from government as well as a favourable official language policy stance. The drawn-out language policy would then require a carefully and well-though out implementation plan to bear fruit.

Beukes (2008:17) argues that "in order to determine possible gaps in implementation, initial conditions (policy goals) should be scrutinised with a view to assessing whether and how 'predicted consequences' (implementation) have been realised." This is easier said than done especially with regards to language policies in South Africa. To start, policy goals are sometimes elusive by choice. Policy goals are often the product of political leadership, and this further complicates matters. As has been indicated in the case of South Africa, politicians seem to believe that English is a better option when it comes to national unity and integration (Webb, n.d.: 6), global interaction and for practicality in the face of many official languages in South Africa. It is then no wonder that there has been little commitment other than language policy documents coming from the politicians in South Africa in as far as language plurality is concerned. Hence the challenge when it comes to implementation.

Brock-Utne and Holmarsdottir (2004: 68) cite the case of the Kenyan writer Ngugi wa Thiong'o who realised that more people started reading his literary work as soon as he wrote in his mother-tongue, Kikuyu. As the masses started reading his radical plays, he became a threat to government. It was not a surprise that he ended up in prison, as a result of this 'attraction' to his works. This is because the political leadership realised that he was somehow redistributing power from the privileged to the masses through his literary works which were then easily understood. Therefore, English could be maintained by the politicians deliberately as a way of excluding the masses from wrestling actual power from their control. The failure to implement language policies could thus be a deliberate move and thus any discussion regarding language plurality be injected secretly with seeds of destruction by the politicians.

According to Anderson (2011: 210), there is sometimes bitter political struggles that attend to implementation of policies. In South Africa the issue of language domination by English and Afrikaans languages is well known and documented. While the South African Constitution, 1996 (Act 108 of 1996) elevates the nine indigenous African languages to official status, one cannot just say that this happens without any kind of resistance. Resistance may sometimes be covert in nature. Resistance could be aimed at derailing the plans the ruling party may have in as far as implementation of language policies is concerned. The question to be asked here is, was there enough interaction and consultation with important stakeholders to arrive at this language policy? Judging from statements made by structures such as the South African Translators' Institute, perhaps government could have done even better on this important aspect of consultation, to avoid resistance which may be justifiable, under the circumstances.

While the language policy looks good on paper, it is silent about the rewards for implementing the policy as well as the penalties for failure to implement. It should not therefore be a surprise that for example on 26 April 2013, government issued proposed Regulations on Use of Official Languages Act, 2012 (Act No. 12 of 2012). Amongst other stipulations, was that all national departments, national public entities and national public enterprises (except those exempted in terms of section 12 of the Act) were supposed to establish language units as contemplated in section 7 of the Act, within 3 months of the coming into effect of these Regulations. Since then, almost a decade now, seemingly very little if anything has been happening and government does not seem to take drastic measured to those who do not comply. In short, there is no carrot and also no stick, attached to the implementation of this policy.

The Act will be applicable in every national department, national public entity and national public enterprise, other than a national public entity and national public enterprise exempted in terms of section 12 of the Act. While this is an excellent place to start, the Act is silent about the private sector. The private sector in South Africa is an important component of the South African life and continues to use English and Afrikaans almost exclusively, in communication. While it is understood that the private sector, just like private individuals has a right to choose which language to use, the South African situation and context demands that government must intervene and lead this process. There are still instances, for example, where important contracts are signed by less educated Africans in some companies without clearly understanding what they are putting themselves into as a result of language that they do not understand. And if those contracts could be written in the languages understandable to those wanting to enter into such contracts, some may think twice about signing those 'unfair' contracts, perhaps even resulting in some companies losing income. Hence there is a possible love-hate relationship between the private sector and the implementation of this language policy. 
Funding is another challenge with regards to implementation. For example, establishing language units would require the employment of staff as well as securing of administrative resources. Government must therefore have a sustainable financial plan. PanSALB and other language structures are examples of determinations where government has been dogged by financial constraints. Since government was dragged to the court before this Act (Use of Official Languages Act, 2012) was passed, chances are enactment of this Act was done to save face and appease the masses who gradually perceived their government as having lost track of its moral ground and stance as a champion of human rights.

\section{Gearing Towards Successfully Implementing the Policy}

Given the above discussion in 5, above, clearly something needs to be done to assist in ensuring that this policy becomes a success. Grin (2003:91) raises three important issues which are crucial in a good policy, which I believe should guide the implementation process, viz. effectiveness, cost-effectiveness as well as democracy. A brief discussion about these crucial aspects in relation to the South African situation follows below:

\subsection{Effectiveness}

Effectiveness refers to effort that produces intended results. In other words, in the case of a language policy, that policy can produce results expected in that specific policy. In the case of language policy, this is not an easy exercise because of several variables associated with effectiveness. In the case of South Africa, the effectiveness or successful implementation of the policy, Use of Official Language Act, 2012, can only be effective in terms of the impact it has on the users of African languages especially, those who were historically denied such an opportunity in the past. Effectiveness or successful implementation cannot serve its intended function if it could be viewed only in terms of some vague official government perspective.

\subsection{Cost-effectiveness}

Cost-effectiveness means that something is of a good value considering the amount of resources spent on it. In the case of the policy for example, resources used may include time spent by the officials on administering the policy as well. Expensive policies are rarely sustainable, more so language policies that need to compete for resources with other policies that may be viewed as more important than languages, for example, housing for the nation. Also, cost-effectiveness will go a long way towards reducing resistance from those who may feel that the language policy is going to take a larger piece of the financial cake, and therefore resist successful implementation of this (language) policy.

\subsection{Democracy}

A policy is usually a product of a political process that seeks to achieve freedom and equality amongst people, where power is in the hands of the elected few representatives, or directly in the people themselves. In the case of this Act under discussion, the important issue is that politicians are not in offices for themselves but are there to satisfy the needs of the electorate. The wish of majority of the people dictates what Act is desirable or successfully implemented, and what is not.

Based on the matters discussed above, the following issues are therefore recommended as way of minimising constraints in ensuring that Use of Official Language Act, 2012 becomes a reality in the Republic of South Africa:

- Acknowledgement that policy development is a political process, and therefore requires a full buy-in from the political leaders. Ignoring the active role of politicians in language policy development is like shooting one's foot, since their commitment is needed to fully implement the policy

- Making academic commentaries aimed at raising awareness on the importance of African languages, particularly, in South Africa. The issue of using African languages is not an end in itself but should be aimed at developing a particular linguistic behaviour. Using African languages does not preclude one from knowing English, for example

- Developing a carrot and stick method with regards to policy implementation. An issue such as the reward for complying with the language policy is important and must be used as a carrot by the government to encourage officials to comply. In the same vein, those who deliberately violate the Act must be punished. From this stance, policy shortcomings could be identified and further relevant Acts or Amendments and other Regulations be put in place, to ensure that matters outstanding are addressed

- The issue of the private sector is crucial. A legislation needs to be developed, or an amendment be done in the current Act. A similar approach of carrot and stick method could be applied to encourage the private sector to participate and co-operate in making South Africa a truly multilingual country 
- Government needs to seek funding that will assist in implementing this policy. There are political, economic and social spin-offs to be reaped from successfully implementing this Act. If language is taken seriously for what it could achieve, private sector could also assist in making funds available to implement this policy

- Encouragement of active participation of stakeholders in language issues. This is important to avoid future serious challenges such as resistance to policies. If affected people participate in the language development process, chances are they will support the policy.

\section{Conclusion}

The intentions of the government are clear in introducing this Act called, Use of the Official Languages Act, 2012. The Act takes a different and radical direction in the development of the official languages, especially the African languages in South Africa. While no Act can be labelled perfect, however, this Act creates a better language approach for better communication at all levels in South Africa. The words of Anderson (2011: 209), that enacting a policy is not the same as declaring a policymaking process as concluded, holds true. It is therefore important that any policy enacted must be followed up carefully with adequate resources to ensure that it succeeds for the whole South African country, and indeed with spinoffs for the whole continent of Africa.

\section{References}

Alexander, N. (2004). The politics of language planning in post-apartheid South Africa. Language Problems and Language Planning, 28(2). John Benjamins Publishing Company, 113-130. https://doi.org/10.1075/lplp.28.2.02ale

Anderson, J. E. (2011). Public policymaking: An introduction. Wadsworth Cengage Learning: USA.

Beukes, A. (2008). Language policy implementation in South Africa: How Kempton Park's great expectations are dashed in Tshwane. in Stellenbosch Papers in Linguistics, 38, 1-26. https://doi.org/10.5774/38-0-20

Brock-Utne, B., \& Holmarsdottir, H. B. (2004). Language policies and practices in Tanzania and South Africa: problems and challenges. in International journal of Educational Development, 24. Elsevier Ltd, 67-83. https://doi.org/10.1016/j.ijedudev.2003.10.002

De Kadt, J. (2005). Language Development in South Africa - Past and Present. Paper presented for LSSA Conference, 6-8 July 2005, 1-30.

Fox, W., \& Bayat, M. S. (2012). A Guide to Managing Research. Cape Town: Juta.

Grin, F. (2003). Language Policy Evaluation and the European Charter for Regional or Minority Languages. Great Britain: Palgrave Macmillan. https://doi.org/10.1057/9780230502666

Hill, L. (2010). Language status: On the limits of language planning. Stellenbosch Papers in Linguistics, 39, 41-58.

Jacobs, S., Power, G., \& Calland, R. (2001). Real politics: the wicked issues. Cape Town: Idasa.

Kaschula, R. H., \& Docrat, Z. (2015). Strategy for Multilingual Success. Supplement to Mail and Guardian, March 6 to 12 2015, p. 4.

Maphalala, J. (2000). Public Policy and African Languages: the case of isiZulu. In Multilingualism and Government. Van Schaik Publishers: Pretoria

Ngcobo, M. N. (2007). Language planning, Policy implementation in South Africa. Pretoria: University of South Africa.

Romaine, S. (1994). Language in Society. Great Britain: Oxford University Press.

Schmied, J. (1991). English in Africa: An Introduction. United States of America” Longman Inc.

The Constitution of the Republic of South Africa, 1996 (Act 108 of 1996). Pretoria: Government Printers.

Webb, V. (n.d.) Language Management in South Africa: What is going wrong? University of Pretoria: Centrepol.

Wright, L. (2002). 'Mother tongue, Other tongue: Law, Learning and Literature'. Keynote Address of the $14^{\text {th }}$ English Academy Conference, held in University of Pretoria on 4-6 April 2002. Pretoria. www.iol.co.za/news/politics/minister-dissolves-languages-board-1970549 [Accessed: 18/11/2019]

\section{Copyrights}

Copyright for this article is retained by the author(s), with first publication rights granted to the journal.

This is an open-access article distributed under the terms and conditions of the Creative Commons Attribution license which permits unrestricted use, distribution, and reproduction in any medium, provided the original work is properly cited. 